\title{
Parcelamento e fontes de nitrogênio na qualidade fisiológica de sementes de trigo
}

\author{
Splitting and nitrogen sources in the physiological quality of wheat seed
}

\section{Tiago Olivoto ${ }^{1}$, Maicon Nardino ${ }^{1}$, Ivan Ricardo Carvalho ${ }^{2 *}$, Mauricio Ferrari ${ }^{2}$, Alan Junior de Pelegrin ${ }^{2}$, Vinícius Jardel Szareski² e Velci Queiróz de Souza ${ }^{3}$ \\ Submissão: 23/12/2015 / Aceite: 15/03/2017}

\section{RESUMO}

Diferentes fontes e manejos parcelados de nitrogênio podem aumentar a disponibilidade, a absorção e a assimilação deste nutriente pelas plantas, favorecendo o acúmulo de $\mathrm{N}$ nos grãos. No entanto, pouco se sabe sobre a influência destes fatores na qualidade fisiológica de sementes de trigo (Triticum aestivum L). Dentro deste contexto, o objetivo deste trabalho foi avaliar a resposta de diferentes fontes e parcelamentos de nitrogênio aplicado em cobertura na qualidade fisiológica das sementes de trigo. $\mathrm{O}$ experimento foi conduzido em delineamento de blocos completos casualizados em esquema de parcelas subdivididas com três cultivares de trigo (TBIO Mestre, TBIO Iguaçu e Quartzo), três fontes de nitrogênio (ureia, nitrato de amônio e ureia líquida) aplicadas em cinco parcelamentos (I: afilhamento; II: afilhamento e emborrachamento; III: afilhamento e florescimento; IV: emborrachamento e florescimento e V: afilhamento, emborrachamento e florescimento). O parcelamento do nitrogênio entre os estádios de emborrachamento e florescimento resulta em sementes com maior qualidade fisiológica, pois incrementa o percentual de germinação em $4 \%$ e influencia positivamente os caracteres na primeira contagem de germinação, comprimento de parte aérea, e massa seca de plântula. As fontes de nitrogênio, nitrato de amônia e a ureia fonte líquida, se equiparam com a ureia em relação ao efeito na qualidade fisiológica das sementes, sendo alternativas interessantes para reduzir o custo de produção. As cultivares TBIO Mestre e Quartzo evidenciaram sementes com maior qualidade fisiológica, em função do maior comprimento de radícula e percentual de germinação.
PALAVRAS-CHAVE: adubação nitrogenada, germinação, Triticum aestivum L., vigor.

\begin{abstract}
Different sources and nitrogen management $(\mathrm{N})$ may increase the availability, absorption, and assimilation of this nutrient by plants, favoring the $\mathrm{N}$ accumulation in grains. However, little is known about the influence of these factors on the physiological quality of wheat seeds (Triticum aestivum L.). In this context, the aim of this study was to evaluate the response of different sources and nitrogen fertilization, applied in cover, on the physiological quality of the wheat seeds. The experiment was conducted in a completely randomized block design in a split-design treatment plot with three cultivars of wheat (TBIO Mestre, TBIO Iguaçu and Quartzo), three sources of nitrogen (urea, ammonium nitrate, and liquid urea), applied using five methods: (I: tilling; II: tilling and booting; III: tilling and flowering; IV: booting and flowering and V: tilling, booting and flowering). The nitrogen partitioning between booting and flowering stages results in higher physiological seed quality, since it increases the percentage of germination by $4 \%$ and positively influences the germination count, shoot length, and seedling dry mass. The sources of nitrogen ammonia nitrate and the urea liquid source are equated with urea in relation to the effect on the physiological quality of the seeds, being interesting alternatives to reduce the production cost. The TBIO Mestre and Quartzo cultivars showed seeds with higher physiological quality, due to the greater length of radicle and percentage of germination.
\end{abstract}

KEYWORDS: fertilizing, germination, Triticum

${ }^{1}$ Universidade Federal de Santa Maria, Santa Maria, RS, Brasil.

${ }^{2}$ Universidade Federal de Pelotas, Pelotas, RS, Brasil.

${ }^{3}$ Universidade Federal do Pampa, Dom Pedrito, RS, Brasil.

*Autor para correspondência <carvalho.irc@gmail.com> 
aestivum L.,vigor.

\section{INTRODUÇÃO}

A necessidade de aumento na produção de trigo (Triticum aestivum L.) no Brasil para suprir a demanda interna pelo cereal é fato (SILVEIRA et al. 2010). A qualidade fisiológica das sementes é considerada um dos principais atributos determinantes do potencial produtivo da cultura, dessa forma, sementes com qualidade satisfatória são resultantes do somatório de atributos físicos, sanitários, genéticos e fisiológicos que, quando combinados, resultam em população de plantas uniforme, livre de moléstias, com alto vigor e consequentemente maior rendimento de grãos (FANAN et al. 2006).

O potencial fisiológio das sementes de trigo é determinado pela sua viabilidade, pureza, percentagem de germinação, bem como pela matéria seca das plântulas (WARRAICH et al. 2002). Contudo, estes atributos são influenciados por manejos nutricionais, principalmente do nitrogênio (WARRAICH et al. 2002, GUL et al. 2012). Em trigo, fontes alternativas de nitrogênio, aplicadas em diferentes manejos de parcelamento, trazem resultados benéficos na eficiência de aproveitamento do nutriente pelas plantas, principalmente devido a redução da volatilização da amônia, quando há hidrolização da molécula de ureia (YADVINDER-SINGH et al. 2015).

As plantas assimilam o nitrogênio por meio da absorção de amônio $\left(\mathrm{NH}_{4}^{+}\right)$ou nitrato $\left(\mathrm{NO}_{3}^{-}\right)$pelas raízes, por diferentes mecanismos fisiológicos. As respostas diferenciadas das plantas a absorção de $\mathrm{NH}_{4}^{+}$e $\mathrm{NO}_{3}^{-}$, ocorrem em virtude da disponibilidade destes no solo ser alterada por fatores como potencial de mineralização, nitrificação, temperatura e pluviosidade (JACKSON \& BLOOM 1990). $\mathrm{O} \mathrm{NH}_{4}^{+}$ geralmente mostra variação muito menor, entretanto, apresenta taxas de volatilização que podem atingir até 30\% (HAYASHI et al. 2008), principalmente em condições de baixa precipitação e altas temperaturas (CHEN et al. 2014).

Após absorvidos, os destinos destes nutrientes na planta frequentemente divergem-se, sendo que, o $\mathrm{NH}_{4}^{+}$é rapidamente convertido em aminoácidos, evitando assim, o efeito tóxico causado pelos seus altos níveis. $\mathrm{O} \mathrm{NO}_{3}^{-}$, além de assimilado, pode ser acumulado nos tecidos e reutilizado, quando a oferta de nitrogênio for insuficiente (BLOOM et al. 2012). Este processo, contudo,demanda grande quantidade de energia (STITT et al. 2002) e requer a expressão de genes específicos em resposta a um estímulo de baixa disponibilidade de nitrogênio, que pode diferir entre cultivares (YIN et al. 2014).

A disponiblidade de nitrogênio influencia a composição química da semente, a formação do embrião e das estruturas de reservas, visto que o nitrogênio está intimamente ligado à produção de proteínas e controle de funções metabólicas, os quais são importantes no desenvolvimento inicial do embrião durante a germinação e consequentemente, influenciam no desempenho fisíologico das sementes (KOLCHINSKI \& SCHUCH 2004).

Diversas pesquisas revelaram o efeito benéfico do incremento da adubação nitrogenada na qualidade fisiológica de sementes de trigo, onde as aplicações de nitrogênio em cobertura aumentaram a concentração de proteína nas sementes e resultaram em incremento na germinação, primeira contagem e massa seca de plântula (WARRAICH et al. 2002, GUL et al. 2012, BRZEZINSKI et al. 2014), aveia (KOLCHINSKI \& SCHUCH 2004), painço (ABRANTES et al. 2010) e milho (GONDIM et al. 2006). Contudo, ainda são escassas na literatura informações que revelem os efeitos do parcelamento e de fontes nitrogenadas aplicados em cobertura na qualidade fisiológica de sementes de trigo.

Dentro deste contexto, o objetivo deste trabalho foi avaliar a resposta de diferentes parcelamentos de nitrogênio aplicado em cobertura e fontes nitrogenadas, na qualidade fisiológica das sementes de trigo.

\section{MATERIAL E MÉTODOS}

O experimento foi conduzido na safra agrícola de 2012 na área experimental do Laboratório de Melhoramento Genético e Produção de Plantas da Universidade Federal de Santa Maria, Campus de Frederico Westphalen, RS, nas coordenadas $27^{\circ} 23^{\prime} 48,17^{\prime \prime} \mathrm{S}, 53^{\circ} 25^{\prime} 34,82^{\prime \prime} \mathrm{O}$, com altitude de $460 \mathrm{~m}$. O solo do local é classificado como Latossolo vermelho distrófico (EMBRAPA 2006) e o clima da região caracterizado como subtropical úmido (Cfa) segundo a classificação climática de Köppen. Visando caracterizar as condições climáticas durante o período de condução do experimento, foram coletados dados de temperatura média e precipitação acumulada fornecidos pela Estação Meteorológica Automática do INMET (Código OMM: 86951), localizada 
aproximadamente $500 \mathrm{~m}$ da área experimental (Figura $1)$.

O delineamento experimental foi de blocos completos casualizados, em arranjo de parcelas subdivididas com três repetições. Os tratamentos foram constituídos por três cultivares, sendo elas, TBIO Mestre, TBIO Iguaçu e Quartzo, alocadas nas parcelas. Três fontes de adubação nitrogenada: ureia (45\% de N), nitrato de amônio (33\% de N) e ureia líquida $(32 \%$ de $\mathrm{N})$ e cinco parcelamentos denitrogênio: [I: afilhamento (100\%); II: afilhamento (50\%) e emborrachamento (50\%); III: afilhamento $(50 \%)$ e florescimento (50\%); IV: emborrachamento $(50 \%)$ e florescimento $(50 \%)$ e $\mathrm{V}$ : afilhamento $(33,33 \%)$, emborrachamento $(33,33 \%)$ e florescimento $(33,33 \%)]$, alocados nas subparcelas. Os estádios fenólogicos foram determinados conforme a escala proposta por ZADOKS et al. (1974), e para ambos os parcelamentos a concentração total de nitrogênio aplicado foi de $115 \mathrm{~kg} \mathrm{ha}^{-1}$.

As unidades experimentais referentes a parcela foram compostas por 12 linhas de $63 \mathrm{~m}$ de comprimento, espaçadas com $0,17 \mathrm{~m}$, totalizando uma área de $128,52 \mathrm{~m}^{2}$. As subparcelas foram compostas por 12 linhas com 3,5 m de comprimentos, espaçadas por $0,17 \mathrm{~m}$, inteirando uma área com área de 7,14 $\mathrm{m}^{2}$. A semeadura foi realizada no dia 25 de maio de 2012, por meio de um conjunto trator-semeadora, visando a obtenção de uma densidade de aproximadamente 300 plantas $\mathrm{m}^{-2}$. A adubação de semeadura com nitrogênio, fósforo e potássio (NPK), foi de $16 \mathrm{~kg} \mathrm{ha}^{-1}$ de N, $48 \mathrm{~kg} \mathrm{ha}^{-1}$ de $\mathrm{P}_{2} \mathrm{O}_{5}$ e $24 \mathrm{~kg} \mathrm{ha}^{-1}$ de $\mathrm{K}_{2} \mathrm{O}$. Os tratos culturais foram realizados de maneira preventiva. A colheita foi realizada de forma manual quando os grãos apresentavam aproximadamente $15 \%$ de umidade, levando-se em consideração a área útil de cada subparcela $\left(3,4 \mathrm{~m}^{2}\right)$, caracterizada por oito linhas centrais, excluído 0,5 metros de cada extremidade. A trilha das sementes foi realizada com auxílio de debulhador, com sistema de debulha axial, evitandose danos mecânicos as sementes.

A qualidade fisiológica das sementes foi avaliada a partir das seguintes análises:

1) Teste de Germinação: realizado com quatro repetições de 100 sementes para cada unidade experimental. As sementes foram acomodadas com a radícula voltada para baixo em duas folhas e cobertas com uma folha de papel "germitest" umedecido com água deionisada com volume equivalente a 2,5 vezes sua massa seca. Foram confeccionados rolos, os quais foram envolvidos por saco plástico devidamente vedado a fim de manter a umidade interna. Estes, foram acomodados em câmaras de germinação do tipo B.O.D. com temperatura de $20 \pm 2{ }^{\circ} \mathrm{C}$ e fotoperíodo de 12 horas diárias de luz, fornecida por lâmpadas do tipo fluorescente. As avaliações foram realizadas no quarto dia, sendo contadas as sementes que possuíam radícula e parte aérea visíveis (primeira contagem de germinação - PCG) e no oitavo dia, sendo contadas as plântulas normais (germinação - G), conforme as Regras de Análise de Sementes (BRASIL 2009).

2) Comprimento de parte aérea (CPA): realizado conjuntamente com o teste de germinação, no oitavo dia após a instalação mensurou-se com auxílio de uma régua graduada o comprimento da parte área de dez plântulas de cada repetição, após calculou-se a média de cada repetição, sendo os valores expressos em centímetros.

3) Comprimento de radicular (CR): realizado conjuntamente com o teste de germinação, no oitavo dia após a instalação do teste, mediu-se com auxílio de régua graduada o comprimento da radícula em dez plântulas de cada repetição, realizando-se a média da repetição, sendo os valores expressos em centímetros. 4) Massa seca de plântula (MS): cada uma das dez plântulas de cada unidade experimental foi acomodada em sacos de papel devidamente identificados e levados para estufa a $65^{\circ} \mathrm{C}$ com circulação de ar, até atingirem massa constante, sendo após realizada a pesagem em balança de precisão. Os resultados foram expressos em gramas.

Os dados foram previamente analisados quanto a presença de outliers e o diagnóstico da normalidade. Posteriormente, foi realizada análise de variância conjunta. Havendo interação significativa (cultivares $\mathrm{x}$ fonte nitrogenada $\mathrm{x}$ parcelamento de nitrogênio), foram desmembrados os efeitos simples para cada variável. As variáveis que não revelaram interação significativa, foram comparadas aos efeitos principais pelo teste Tukey $(p<0,05)$. As análises estatísticas foram realizadas com o auxílio do software Genes (CRUZ 2013).

\section{RESULTADOS E DISCUSSÃO}

A análise de variância conjunta revelou significancia $(p<0,05)$ para interação cultivares $x$ fonte nitrogenada $\mathrm{x}$ parcelamento de nitrogênio para as variáveis, primeira contagem de germinação (PCG), percentual de germinação $(\mathrm{G})$, comprimento da parte 


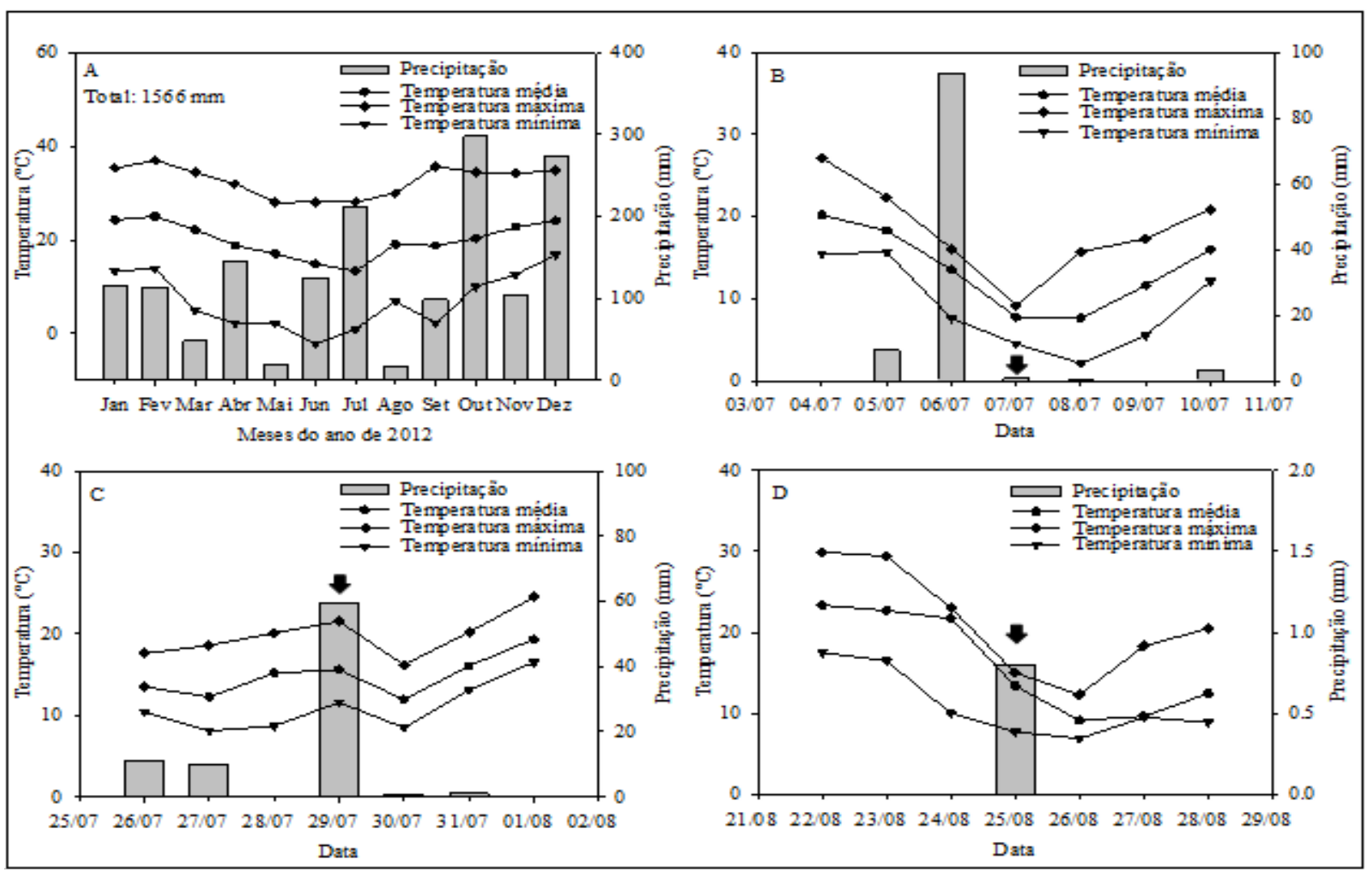

Figura 1.Valores de precipitação acumulada (colunas), temperaturas médias, máximas absolutas e mínimas absolutas (linhas) observadas no ano de 2012 (A), três dias antes e três dias após cada aplicação de nitrogênio nos estádios de afilhamento (B), emborrachamento (C) e florescimento (D). As setas indicam o dia que as aplicação de nitrogenio foram realizadas em cada estádio.

Figure 1. Values of accumulated precipitation (columns), average temperatures, absolute maximums and absolute minimums (lines) observed in 2012 (A), three days before and three days after each application of nitrogen in the tilling stages $(B)$, drunk $(C)$ and flowering $(D)$. The arrows indicate the day the application of nitrogen was carried out at each stage.

aérea (CPA), comprimento radicular (CR) e massa seca de plântula (MS). Estes resultados demonstram que o comportamento das variáveis analisadas são dependentes da cultivar, da fonte nitrogenada e do parcelamento de nitrogênio aplicado em cobertura.

O ano de 2012 apresentou precipitação acumulada de $1566 \mathrm{~mm}$, sendo que nos meses de condução do experimento (maio a novembro), o montante acumulado foi de $852 \mathrm{~mm}$, com o maior volume observado no mês de outubro (297 mm). O mês de Julho apresentou precipitação de 210 $\mathrm{mm}$, dentro da normalidade para o local (Figura 1A). A tempertura média anual registada foi de 20,1 ${ }^{\circ} \mathrm{C}$, sendo que, nos meses de Maio a Setembro as temperaturas médias mensais foram de 17,1; 14,6; 13,3; 19,0 e $18,8^{\circ} \mathrm{C}$, respectivamente. Dessa forma, evidenciou-se que as condições meteorológicas de precipitação e temperatura do ar ocorridas durante a condução do experimento estão em conformidade com as caracteristicas climatológias da região, que de acordo com a classificação de Köppen, o clima da região é, subtropical úmido com temperatura média anual de $19,1^{\circ} \mathrm{C}$ e temperatura média no mês mais frio do ano $\leq 13{ }^{\circ} \mathrm{C}$, e com precipitação média anual de $1735 \mathrm{~mm}$ (ALVARES et al. 2013).

As aplicações de nitrogênio no estádio de afilhamento (Figura 1B), coicidiram com um período de alta umidade no solo, sendo que após a aplicação, ocorreu uma precipitação de cerca de $2 \mathrm{~mm}$. O mesmo pode ser observado para as aplicações no emborrachamento, realizadas após $60 \mathrm{~mm}$ de precipitação (Figura 1C). As aplicações no florescimento, foram realizadas em um período com umidade no solo ideal, entretanto a precipitação acumulada após a aplicação foi de $0,8 \mathrm{~mm}$ em uma semana (Figura 1D). Os valores de temperatura 
média diária no dia das aplicações e nos três dias subsequentes, não ultrapassaram $20^{\circ} \mathrm{C}$ (Figuras $1 \mathrm{~B}$, $1 \mathrm{C}$ e 1D).

A primeira contagem de germinação (PCG) para a cultivar TBIO Mestre, nas fontes ureia e nitrato de amônio revelou que os parcelamentos de nitrogênio II e IV foram superiores aos demais parcelamentos. Entretanto, estes mesmos parcelamentos, evidenciaram menor PCG quando utilizado a fonte de ureia líquida (Tabela 1). Para a cultivar TBIO Iguaçu, a maior PCG foi observada na fonte ureia no parcelamento I, diferentemente do nitrato de amônio, que com o parcelamento deste nutriente em estádios mais jovens da cultivar no afilhamento e emborrachamento (parcelamento II) e em três épocas de aplicação (parcelamento $\mathrm{V}$ ), proporcionaram maior PCG.

A melhor resposta para a ureia utilizada em uma única aplicação no afilhamento pode ser explicada devido sua incorporação no solo, proporcionada pela alta umidade no solo e a ocorrência de precipitação após a aplicação, reduzindo assim sua volatilização. Para a fonte líquida, o parcelamento IV proporcionou a maior PCG. Diferenças entre as fontes de N em cada

Tabela 1. Médias para interação entre cultivares (TBIO Mestre, TBIO Iguaçu, TBIO Quartzo) x parcelamento de nitrogênio em cobertura (I: afilhamento, II: afilhamento e emborrachamento, III: afilhamento e florescimento, IV: emborrachamento e florescimento, e V: afilhamento, emborrachamento e florescimento) x fonte nitrogenada (ureia, nitrato de amônia e líquida) para o carácter primeira contagem de germinação (PCG), em percentagem (\%).

Table 1. Averages for interaction between cultivars (TBIO Mestre, TBIO Iguaçu, TBIO Quartzo) x installments of nitrogen in coverage (I: tilling, II: tilling and booting, III: tilling and flowering, IV: booting and flowering, V: tilling, booting and flowering) x nitrogen source (urea, ammonium nitrate and liquid) for trait first germination count (PCG) in percentage (\%).

\begin{tabular}{cccc}
\hline & & Fonte \\
Parc. & Ureia & Nitrato de amônio & Líquida \\
\hline I & & TBIO Mestre \\
II & $94,50 \mathrm{abA} \alpha$ & $92,25 \mathrm{bcA} \alpha \beta$ & $93,50 \mathrm{aA} \alpha$ \\
III & $97,50 \mathrm{aA} \alpha$ & $95,00 \mathrm{abA} \alpha$ \\
IV & $94,25 \mathrm{abA} \alpha$ & $89,25 \mathrm{cB} \beta$ & $89,75 \mathrm{abB} \beta$ \\
V & $97,00 \mathrm{aA} \alpha$ & $95,00 \mathrm{abA} \alpha$ & $93,00 \mathrm{abAB} \beta$ \\
& $92,75 \mathrm{bB} \alpha$ & $97,00 \mathrm{aA} \alpha$ & $89,25 \mathrm{bB} \beta$ \\
I & & TBIO Iguaçu & $93,00 \mathrm{abAB} \alpha \beta$ \\
II & $97,00 \mathrm{aA} \alpha$ & $89,50 \mathrm{bB} \beta$ & \\
III & $89,75 \mathrm{cB} \beta$ & $96,75 \mathrm{aA} \alpha$ & $93,75 \mathrm{bcA} \alpha$ \\
IV & $95,25 \mathrm{abA} \alpha$ & $93,50 \mathrm{abA} \alpha$ \\
V & $92,00 \mathrm{bcB} \beta$ & $90,00 \mathrm{bB} \beta$ & $94,75 \mathrm{abcA} \alpha$ \\
& $92,75 \mathrm{bcA} \alpha$ & $94,25 \mathrm{aA} \alpha$ & $98,00 \mathrm{aA} \alpha$ \\
I & & Quartzo & $91,50 \mathrm{cA} \beta$ \\
II & $96,50 \mathrm{aA} \alpha$ & $94,50 \mathrm{abA} \alpha$ \\
III & $90,25 \mathrm{bB} \beta$ & $95,25 \mathrm{abA} \alpha$ \\
IV & $95,00 \mathrm{aA} \alpha$ & $96,75 \mathrm{abA} \alpha$ \\
V & $94,75 \mathrm{aB} \alpha \beta$ & $98,00 \mathrm{aAB} \alpha$ & $92,75 \mathrm{bA} \alpha$ \\
\hline CV $(\%)$ & $96,75 \mathrm{a} \mathrm{A} \alpha$ & $93,00 \mathrm{bA} \alpha$ & $97,00 \mathrm{aA} \alpha$ \\
\hline & & 3,12 & $97,50 \mathrm{aA} \alpha$ \\
\hline
\end{tabular}

Médias seguidas pela mesma letra minúscula (a) na coluna para parcelamento de nitrogênio em cobertura, maiúscula (A) na linha para fonte nitrogenada, e gregas ( $\alpha$ e $\beta$ ) para cultivares, não diferem estatisticamente pelo teste Tukey à $5 \%$ de probabilidade de erro. 
parcelamento foram observadas, onde no parcelamento I, a ureia e a fonte líquida apresentaram as menores médias. Já para o parcelamento II, o nitrato e a fonte líquida apresentaram os incrementos de PCG, para o parcelamento IV a fonte de adubação de ureia líquida foi superior às demais fontes utilizadas.

Com relação a cultivar Quartzo quando se utilizou a fonte ureia em única aplicação diferiu estatisticamente do parcelamento II, sendo caracterizado com a menor PCG (Tabela 1). Para o nitrato de amônio a aplicação parcelada em três épocas (V) proporcionou um menor percentual de sementes germinadas na primeira contagem, ao passo que para a ureia líquida, o parcelamento I apresentou a menor média. Este comportamento contrastante para a PCG, pode estar relacionado com a dinâmica de absorção e assimilação das diferentes fontes de $\mathrm{N}$ disponibilizadas para as cultivares. Pesquisas revelaram que plantas de trigo fertilizadas com $12 \mathrm{mM}$ de amônia apresentaram redução de $15 \%$ na atividade fotossintética, $11 \%$ na transpiração e $5,7 \%$ na concentração intercelular de $\mathrm{CO}_{2}$ quando comparada a mesma concentração de nitrato, revelando que as atividades metabólicas básicas são influenciadas pelas diferentes fontes nitrogenadas (CRAMER \& LEWIS 1993).

$\mathrm{Na}$ maioria das espécies, tanto as raízes quanto a parte aérea têm capacidade de assimilar nitrato. Quando as raízes recebem pequenas quantidades deste nutriente, a redução do nitrato para assimilação se dá primeiramente nas raízes, contudo, quando o suprimento deste nutriente aumenta, uma maior proporção da quantidade absorvida é translocada para a parte aérea para posteriormente ser assimilada (BLOOM et al. 2012). Isto pode explicar o menor vigor das sementes quando a quantidade de nitrato foi dividida em três estádios (parcelamento V). Entretanto foram observados que a PCG oscila em razão da cultivar, da fonte de adubação e do parcelamento, sendo necessária cautela e a análise dos demais componentes da qualidade fisiológica para inferir sobre quais tratamentos proporcionariam maior qualidade fisiológica nas sementes.

Os resultados obtidos para a germinação $(\mathrm{G})$ revelaram comportamento diferenciado quando comparado com a PCG. Para a cultivar TBIO Mestre, não foram observadas diferenças estatísticas entre os parcelamentos para as três fontes (Tabela 2). Para a cultivar TBIO Iguaçu na fonte ureia, a maior germinação $(96 \%)$ ocorreu no parcelamento I, caracterizado por uma única aplicação no afilhamento. Quando a fonte de adubação foi o nitrato, a maior germinação $(94,5 \%)$, foi observada no parcelamento II, já para ureia líquida, o parcelamento IV, proporcionou o aumento na germinação (97\%). Os resultados revelam que o parcelamento do nitrato de amônio e da fonte líquida com os parcelamentos II e IV respectivamente, proporcionaram maiores percentuais de germinação para o TBIO Iguaçu, quando comparados com os outros parcelamentos para estas fontes.

Para a cultivar Quartzo com a fonte ureia, as maiores médias de germinação foram observadas para os parcelamentos de nitrogênio I, IV e V $(97 \%, 95 \%$ e $97 \%$, respectivamente) (Tabela 2). Os parcelamentos II e III apresentaram os menores percentuais de germinação, bem como se apresentaram inferiores quando comparadas com o parcelamento de nitrato e a ureia fonte líquida. Os resultados observados indicam que o parcelamento da ureia em estádios iniciais (parcelamento II e III), proporcionaram uma redução na germinação das sementes do Quartzo, ao passo que para o nitrato, o único parcelamento que diferenciou foi o $\mathrm{V}$, apresentando a menor germinação $(90 \%)$. Os resultados revelaram que o parcelamento do nitrato, não foi benéfico para o incremento da germinação desta cultivar. Quando comparada a ureia fonte líquida, uma única aplicação (I), proporcionou menor $\mathrm{G}$, ao passo que entre os outros parcelamentos não foram observadas diferenças (Tabela 2).

O processo de germinação depende basicamente da capacidade da semente absorver água (DODD \& DONOVAN 1999) e das reservas armazenadas no endosperma serem convertidas e mobilizadas para suporte energético do embrião (LIN \& KAO 1995). No entanto, a constituição genética da cultivar e sua interação com o ambiente em que foi originada, podem afetar o percentual de germinação das sementes (DODD \& DONOVAN 1999), principalmente devido as mudanças na organização estrutural e síntese proteica no momento da germinação do embrião (RAMAGOPAL 1990). Em nível fisiológico, a formação de proteínas, importantes no processo de germinação das sementes, envolve mecanismos de absorção de nitrogêniopelas raízes, acúmulo nos órgãos vegetativos e posterior remobilização para os grãos para a formação e configuração proteica (TRIBOÏ et al. 2003). Este nitrogênio remobilizado é responsável por cerca de $80 \%$ do conteúdo total do nutriente no grão (SUPRAYOGI et al. 2011), magnitude esta que pode ser influenciada devido a eficiência de absorção 
Tabela 2. Médias para interação entre cultivares (TBIO Mestre, TBIO Iguaçu, TBIO Quartzo) x parcelamento de nitrogênio em cobertura (I: afilhamento, II: afilhamento e emborrachamento, III: afilhamento e florescimento, IV: emborrachamento e florescimento, e V: afilhamento, emborrachamento e florescimento) x fonte nitrogenada (ureia, nitrato de amônia e líquida) para o carácter percentagem de germinação $(\mathrm{G})$ em percentagem $(\%)$.

Table 2. Averages for interaction between cultivars (TBIO Mestre, TBIO Iguaçu, TBIO Quartzo) x installments of nitrogen in coverage (I: tilling, II: tilling and booting, III: tilling and flowering, IV: booting and flowering, V: tilling, booting and flowering) x nitrogen source (urea, ammonium nitrate and liquid) for the percentage germination $(G)$, in percentage (\%).

\begin{tabular}{cccc}
\hline & & \multicolumn{3}{c}{ Fonte } \\
Parc. & Ureia & Nitrato de amônio & Líquida \\
\hline I & & TBIO Mestre \\
II & $98,00 \mathrm{aA} \alpha$ & $95,00 \mathrm{aA} \alpha$ \\
III & $98,00 \mathrm{aA} \alpha$ & $95,00 \mathrm{aA} \alpha$ & $98,00 \mathrm{aA} \alpha$ \\
IV & $95,00 \mathrm{aA} \alpha$ & $97,00 \mathrm{aA} \alpha$ & $95,00 \mathrm{aA} \alpha$ \\
V & $98,00 \mathrm{aA} \alpha$ & $98,00 \mathrm{aA} \alpha$ & $97,00 \mathrm{aA} \alpha$ \\
& $96,00 \mathrm{aA} \alpha \beta$ & $98,00 \mathrm{aA} \alpha$ & $95,00 \mathrm{aA} \alpha$ \\
I & & TBIO Iguaçu & $96,00 \mathrm{aA} \alpha$ \\
II & $96,00 \mathrm{aA} \alpha$ & $88,00 \mathrm{abB} \beta$ & $94,00 \mathrm{abA} \alpha$ \\
III & $87,00 \mathrm{bB} \beta$ & $94,00 \mathrm{aA} \alpha$ & $93,00 \mathrm{abAB} \alpha$ \\
IV & $92,00 \mathrm{abA} \alpha$ & $86,00 \mathrm{bB} \beta$ & $92,00 \mathrm{bA} \beta$ \\
V & $89,00 \mathrm{bB} \beta$ & $88,00 \mathrm{abB} \beta$ & $97,00 \mathrm{aA} \alpha$ \\
& $91,00 \mathrm{abA} \beta$ & $88,00 \mathrm{abA} \beta$ & $76,00 \mathrm{cB} \beta$ \\
I & & Quartzo & \\
II & & $96,00 \mathrm{aA} \alpha$ & $87,00 \mathrm{bB} \beta$ \\
III & $97,00 \mathrm{aA} \alpha$ & $94,00 \mathrm{abA} \alpha$ & $94,00 \mathrm{aA} \alpha$ \\
IV & $88,00 \mathrm{bB} \beta$ & $95,00 \mathrm{aA} \alpha$ & $97,00 \mathrm{aA} \alpha$ \\
V & $85,00 \mathrm{bB} \beta$ & $96,00 \mathrm{aA} \alpha$ & $97,00 \mathrm{aA} \alpha$ \\
\hline CV (\%) & $95,00 \mathrm{aA} \alpha$ & $90,00 \mathrm{bB} \beta$ & $93,00 \mathrm{aAB} \alpha$ \\
\hline
\end{tabular}

Médias seguidas pela mesma letra minúscula (a) na coluna para parcelamento de nitrogênio em cobertura, maiúscula (A) na linha para fonte nitrogenada, e gregas ( $\alpha$ e $\beta$ ) para cultivares, não diferem estatisticamente pelo teste Tukey à $5 \%$ de probabilidade de erro.

e aproveitamento deste nutriente. Pesquisas avaliando o efeito do parcelamento de nitrogênio durante a fase de panícula em arroz em consórcio com trigo revelaram que a aplicação antecipada de nitrogênio, reduz significativamente as perdas deste nutriente, assegurando uma alta taxa de absorção (XU et al. 2015).

O comprimento da parte aérea (CPA) se destaca como uma importante característica no sentido de facilitar a exteriorização das plântulas (CRUZ \& MILACH 2004). O CPA da cultivar TBIO Mestre não apresentou diferenças significativas em função das fontes e parcelamentos de nitrogênio estudados
(Tabela 3). Para o TBIO Iguaçu, a ureia, influenciou positivamente para o maior CPA $(9,67 \mathrm{~cm})$, quando dividida em três aplicações (parcelamento V). Para a fonte nitrato de amônio, a aplicação no afilhamento proporcionou maior comprimento da parte aérea, contudo não diferenciando do parcelamento V. Para a cultivar Quartzo não foram observadas diferenças significativas entre os parcelamentos de adubação para as fontes de nitrogênio ureia e fonte líquida, bem como entre as fontes em cada parcelamento. Com relação ao nitrato de amônio, o maior CPA foi observado para os parcelamentos I, II e V. Os resultados revelaram o comportamento diferenciado de cada cultivar frente 
as fontes e parcelamento do nitrogênio aplicado em cobertura.

Para o comprimento da radícula (CR) do TBIO Mestre não foram observadas diferenças entre os parcelamentos nitrogenados para a fonte ureia (Tabela 4). Para o nitrato de amônio, o maior CR foi observado no parcelamento II $(10,85 \mathrm{~cm})$, com diferenças significativas apenas do parcelamento IV $(8,85 \mathrm{~cm})$. Para a fonte líquida, o parcelamento que se destacou foi o I $(9,40 \mathrm{~cm})$, sendo semelhante com o parcelamento II e IV. Esta fonte proporcionou menores CR quando comparada com a ureia e o nitrato para os parcelamentos III e V. Com relação ao TBIO Iguaçu (Tabela 4), foi observado que a fonte ureia e fonte líquida proporcionaram maior $\mathrm{CR}$ quando aplicadas no emborrachamento e no florescimento (parcelamento IV). Para o nitrato de amônio, não ocorreram diferenças entre os parcelamentos (Tabela 4). Para a cultivar Quartzo, a ureia apresentou diferença significativa para o parcelamento III, caracterizado por um menor CR $(4,96 \mathrm{~cm})$, entre os outros parcelamentos, não foram observadas diferenças. Já para o nitrato de amônio, o maior comprimento de radícula $(10,79 \mathrm{~cm})$ foi observado no

Tabela 3. Médias para interação entre cultivares (TBIO Mestre, TBIO Iguaçu, TBIO Quartzo) x parcelamento de nitrogênio em cobertura (I: afilhamento, II: afilhamento e emborrachamento, III: afilhamento e florescimento, IV: emborrachamento e florescimento, e V: afilhamento, emborrachamento e florescimento) x fonte nitrogenada (ureia, nitrato de amônia e líquida) para o carácter comprimento da parte aérea (CPA), em centímetros $(\mathrm{cm})$.

Table 3. Averages for interaction between cultivars (TBIO Mestre, TBIO Iguaçu, TBIO Quartzo) x installments of nitrogen in coverage (I: tilling, II: tilling and booting, III: tilling and flowering, IV: booting and flowering, $V$ : tilling, booting and flowering) x nitrogen source (urea, ammonium nitrate and liquid) for the length of the aerial (CPA), in centimeters (cm).

\begin{tabular}{|c|c|c|c|}
\hline \multirow{3}{*}{ Parc. } & \multicolumn{3}{|c|}{ Fonte } \\
\hline & Ureia & Nitrato de amônio & Líquida \\
\hline & \multicolumn{3}{|c|}{ TBIO Mestre } \\
\hline I & $8,83 \mathrm{aA} \alpha$ & $9,39 \mathrm{aA} \alpha \beta$ & $9,42 \mathrm{aA} \alpha$ \\
\hline II & $8,25 \mathrm{aA} \alpha$ & $9,54 \mathrm{aA} \alpha$ & $9,74 \mathrm{aA} \alpha$ \\
\hline III & $8,94 \mathrm{aA} \alpha$ & $8,62 \mathrm{aA} \alpha$ & $9,73 \mathrm{aA} \alpha \beta$ \\
\hline IV & $8,81 \mathrm{aA} \alpha$ & $8,34 \mathrm{aA} \alpha$ & $8,70 \mathrm{aA} \alpha$ \\
\hline \multirow[t]{2}{*}{$\mathrm{V}$} & $9,35 \mathrm{aA} \alpha$ & $8,88 \mathrm{aA} \alpha$ & $10,21 \mathrm{aA} \alpha$ \\
\hline & \multicolumn{3}{|c|}{ TBIO Iguaçu } \\
\hline I & $8,73 \mathrm{abA} \alpha$ & $10,31 \mathrm{aA} \alpha$ & $8,71 \mathrm{bcA \alpha}$ \\
\hline II & $7,31 \mathrm{bA} \alpha$ & $8,31 \mathrm{bA} \alpha$ & $8,84 \mathrm{bcA} \alpha$ \\
\hline III & $7,81 \mathrm{abB} \alpha$ & $6,31 \mathrm{cB} \beta$ & $11,5 \mathrm{aA} \alpha$ \\
\hline IV & $7,36 \mathrm{bB} \alpha$ & $7,81 \mathrm{bcB} \alpha$ & $9,77 \mathrm{abA} \alpha$ \\
\hline \multirow[t]{2}{*}{$\mathrm{V}$} & $9,67 \mathrm{aA} \alpha$ & $9,01 \mathrm{abA \alpha}$ & $7,08 \mathrm{cB} \beta$ \\
\hline & \multicolumn{3}{|c|}{ Quartzo } \\
\hline I & $8,23 \mathrm{aA} \alpha$ & $8,07 \mathrm{abA} \beta$ & $7,56 \mathrm{aA} \alpha$ \\
\hline II & $8,97 \mathrm{aA} \alpha$ & $9,08 \mathrm{abA} \alpha$ & $8,93 \mathrm{aA} \alpha$ \\
\hline III & $7,43 \mathrm{aA} \alpha$ & 7,63 bA $\alpha \beta$ & $8,11 \mathrm{aA} \beta$ \\
\hline IV & $7,97 \mathrm{aA} \alpha$ & $7,02 \mathrm{bA} \alpha$ & $8,06 \mathrm{aA} \alpha$ \\
\hline $\mathrm{V}$ & $9,04 \mathrm{aA} \alpha$ & $9,53 \mathrm{aA} \alpha$ & 8,89 aA $\alpha \beta$ \\
\hline
\end{tabular}

*Médias seguidas pela mesma letra minúscula (a) na coluna para parcelamento de nitrogênio em cobertura, maiúscula (A) na linha para fonte nitrogenada, e gregas $(\alpha$ e $\beta$ ) para cultivares, não diferem estatisticamente pelo teste Tukey à $5 \%$ de probabilidade de erro. 
Tabela 4. Médias para interação entre cultivares (TBIO Mestre, TBIO Iguaçu, TBIO Quartzo) x parcelamento de nitrogênio em cobertura (I: afilhamento, II: afilhamento e emborrachamento, III: afilhamento e florescimento, IV: emborrachamento e florescimento, e V: afilhamento, emborrachamento e florescimento) x fonte nitrogenada (ureia, nitrato de amônia e líquida) para o carácter comprimento da radícula $(\mathrm{CR})$, em centímetros $(\mathrm{cm})$.

Table 4. Averages for interaction between cultivars (TBIO Mestre, TBIO Iguaçu, TBIO Quartzo) x installments of nitrogen in coverage (I: tilling, II: tilling and booting, III: tilling and flowering, IV: booting and flowering, $V$ : tilling, booting and flowering) $x$ nitrogen source (urea, ammonium nitrate and liquid) for the length of the radical $(C R)$, in centimeters $(\mathrm{cm})$.

\begin{tabular}{cccc}
\hline & & Fonte \\
Parc. & Ureia & Nitrato de amônio & Líquida \\
\hline I & & TBIO Mestre \\
II & $9,73 \mathrm{aA} \alpha$ & $9,38 \mathrm{abA} \alpha$ & $9,40 \mathrm{aA} \alpha$ \\
III & $8,85 \mathrm{aB} \alpha$ & $10,85 \mathrm{aA} \alpha$ & $7,85 \mathrm{abB} \beta$ \\
IV & $10,00 \mathrm{aA} \alpha$ & $9,36 \mathrm{abA} \alpha$ & $7,31 \mathrm{bB} \alpha$ \\
V & $9,89 \mathrm{aA} \alpha$ & $8,95 \mathrm{bA} \alpha$ & $8,7 \mathrm{abA} \alpha$ \\
& $10,42 \mathrm{aA} \alpha$ & $10,19 \mathrm{abA} \alpha$ & $6,91 \mathrm{bB} \alpha$ \\
I & & TBIO Iguaçu & \\
II & $6,77 \mathrm{abA} \beta$ & $5,62 \mathrm{aA} \beta$ & $6,52 \mathrm{bcA} \beta$ \\
III & $4,99 \mathrm{bA} \beta$ & $5,59 \mathrm{aA} \gamma$ & $5,00 \mathrm{cA} \gamma$ \\
IV & $6,20 \mathrm{abAB} \beta$ & $4,54 \mathrm{aB} \beta$ & $7,10 \mathrm{bA} \alpha$ \\
V & $7,11 \mathrm{aB} \beta$ & $5,10 \mathrm{aC} \beta$ & $9,05 \mathrm{aA} \alpha$ \\
& $6,68 \mathrm{abA} \beta$ & $5,68 \mathrm{aA} \beta$ & $4,82 \mathrm{cA} \beta$ \\
I & & Quartzo & \\
II & $8,75 \mathrm{aB} \alpha$ & $10,79 \mathrm{aA} \alpha$ & $7,93 \mathrm{abB} \alpha \beta$ \\
III & $8,71 \mathrm{aA} \alpha$ & $8,61 \mathrm{bA} \beta$ & $9,78 \mathrm{aA} \alpha$ \\
IV & $4,96 \mathrm{bB} \beta$ & $8,00 \mathrm{bA} \alpha$ & $8,33 \mathrm{abA} \alpha$ \\
V & $7,23 \mathrm{aB} \beta$ & $7,97 \mathrm{bAB} \alpha$ & $9,44 \mathrm{aA} \alpha$ \\
\hline CV (\%) & $8,05 \mathrm{aA} \beta$ & $8,50 \mathrm{bA} \alpha$ & $7,12 \mathrm{bA} \alpha$ \\
\hline
\end{tabular}

Médias seguidas pela mesma letra minúscula (a) na coluna para parcelamento de nitrogênio em cobertura, maiúscula (A) na linha para fonte nitrogenada, e gregas ( $\alpha$ e $\beta$ ) para cultivares, não diferem estatisticamente pelo teste Tukey à $5 \%$ de probabilidade de erro.

parcelamento I. Para a ureia líquida o CR apresentouse menor no parcelamento $\mathrm{V}$ (Tabela 4).

Estes resultados revelaram que as cultivares responderam de diferentes formas às fontes $\mathrm{e}$ parcelamentos nitrogenados para o CPA e CR. Pesquisas revelaram que plântulas de trigo apresentam maior relação parte aérea/sistema radicular, quando cultivadas com amônio $(4,26)$, em comparação com nitrato $(2,99)$. Esta diferença está relacionada, principalmente, à maior translocação de carbono da raiz para a parte aérea, sob forma de compostos amino, resultando em uma redução dos recursos de hidratos de carbono nas raízes de plântulas de trigo alimentadas com amônia (CRAMER \& LEWIS 1993).

Ao avaliar a massa seca de plântulas (MS) do TBIO Mestre, foram observadas diferenças entre os parcelamentos apenas para a fonte de adubação com ureia, onde o parcelamento IV proporcionou a menor média $(0,104 \mathrm{~g})$. Entre os parcelamentos I, II, III e V não se observaram diferenças significativas (Tabela 5). Com relação a cultivar TBIO Iguaçu, a fonte ureia apresentou comportamento distinto em comparação com TBIO Mestre, onde o parcelamento 
IV proporcionou para a cultivar TBIO Iguaçu a maior média de MS $(0,139 \mathrm{~g})$. Quando a fonte utilizada foi o nitrato, não se observou diferenças significativas entre os parcelamentos de nitrogênio aplicado em cobertura. Para a fonte ureia líquida, o parcelamento III proporcionou maior acúmulo de MS $(0,135 \mathrm{~g})$. Quando comparado a resposta das cultivares frente as diferentes fontes em cada parcelamento, observouse que apenas o parcelamento IV para a fonte líquida proporcionou menor matéria seca $(0,089$ g). Dessa forma, o fornecimento de nitrogênio nos estádios mais avançados da cultura, resulta em maior acúmulo de nitrogênio nos grãos, o que é expresso pelo percentual de proteína. Com isso, sementes com maior concentração de proteínas dão origem a plantas mais vigorosas, e com maior acúmulo de massa seca, visto que o nitrogênio é o constituinte de biomoléculas na planta, podendo afetar a qualidade das sementes. Isso corrobora com os trabalhos de CARVALHO \& NAKAGAWA (1988), os quais observaram a existência de correlação positiva entre o teor de proteína e o vigor das sementes.

Tabela 5. Médias para interação entre cultivares (TBIO Mestre, TBIO Iguaçu, TBIO Quartzo) x parcelamento de nitrogênio em cobertura (I: afilhamento, II: afilhamento e emborrachamento, III: afilhamento e florescimento, IV: emborrachamento e florescimento, e V: afilhamento, emborrachamento e florescimento) x fonte nitrogenada (ureia, nitrato de amônia e líquida) para o carácter massa seca de plântulas (MS), em gramas (g).

Table 5. Averages for interaction between cultivars (TBIO Mestre, TBIO Iguaçu, TBIO Quartzo) x nitrogen pAverages for interaction between cultivars (TBIO Mestre, TBIO Iguaçu, TBIO Quartzo) x installments of nitrogen in coverage (I: tilling, II: tilling and booting, III: tilling and flowering, IV: booting and flowering, $V$ : tilling, booting and flowering) x nitrogen source (urea, ammonium nitrate and liquid) for the dry mass of seedlings (MS), in grams (g).

\section{Fonte}

\begin{tabular}{cccc} 
Parc. & Ureia & Nitrato de amônio & Líquida \\
\hline I & & TBIO Mestre \\
II & $0,129 \mathrm{aA} \alpha$ & $0,111 \mathrm{aA} \alpha$ & $0,123 \mathrm{aA} \alpha$ \\
III & $0,130 \mathrm{aA} \alpha$ & $0,111 \mathrm{aA} \alpha$ & $0,113 \mathrm{aA} \alpha$ \\
IV & $0,113 \mathrm{abA} \alpha$ & $0,110 \mathrm{aA} \alpha$ & $0,122 \mathrm{aA} \alpha \beta$ \\
V & $0,104 \mathrm{bB} \beta$ & $0,123 \mathrm{aAB} \alpha$ & $0,130 \mathrm{aA} \alpha$ \\
& $0,117 \mathrm{abA} \alpha$ & $0,123 \mathrm{aA} \alpha$ & $0,110 \mathrm{aA} \alpha$ \\
I & & TBIO Iguaçu & \\
II & $0,122 \mathrm{abA} \alpha$ & $0,115 \mathrm{aA} \alpha$ & $0,119 \mathrm{abA} \alpha$ \\
III & $0,114 \mathrm{bA} \alpha$ & $0,120 \mathrm{aA} \alpha$ & $0,109 \mathrm{bcA} \alpha$ \\
IV & $0,123 \mathrm{abA} \alpha$ & $0,131 \mathrm{aA} \alpha$ & $0,135 \mathrm{aA} \alpha$ \\
V & $0,139 \mathrm{aA} \alpha$ & $0,119 \mathrm{aA} \alpha$ & $0,089 \mathrm{cB} \beta$ \\
& $0,114 \mathrm{bA} \alpha$ & $0,124 \mathrm{aA} \alpha$ & $0,123 \mathrm{abA} \alpha$ \\
I & & Quartzo & $0,118 \mathrm{aA} \alpha$ \\
II & $0,109 \mathrm{abA} \alpha$ & $0,121 \mathrm{aA} \alpha$ & $0,118 \mathrm{aA} \alpha$ \\
III & $0,126 \mathrm{aA} \alpha$ & $0,111 \mathrm{aA} \alpha$ & $0,112 \mathrm{aA} \beta$ \\
IV & $0,121 \mathrm{aA} \alpha$ & $0,112 \mathrm{aA} \alpha$ & $0,123 \mathrm{aA} \alpha$ \\
V & $0,100 \mathrm{bB} \beta$ & $0,117 \mathrm{aAB} \alpha$ & $0,117 \mathrm{aAB} \alpha$ \\
\hline CV $(\%)$ & $0,099 \mathrm{bB} \alpha$ & $0,121 \mathrm{aA} \alpha$ & \\
\hline IE & & 12,96 & \\
\hline
\end{tabular}

Médias seguidas pela mesma letra minúscula (a) na coluna para parcelamento de nitrogênio em cobertura, maiúscula (A) na linha para fonte nitrogenada, e gregas $(\alpha$ e $\beta$ ) para cultivares, não diferem estatisticamente pelo teste Tukey à $5 \%$ de probabilidade de erro. 
Com relação a cultivar Quartzo, a fonte ureia revelou as maiores médias de MS nos parcelamentos de nitrogênio II e III $(0,126 \mathrm{~g}$ e $0,121 \mathrm{~g})$, respectivamente, contudo não diferindo estatisticamente do parcelamento I (Tabela 5). Para a fonte nitrato, não foram observadas diferenças significativas entre os parcelamentos de nitrogênio, resposta semelhante à evidenciada para a cultivar TBIO Iguaçu. Estudos realizados por PRANDO et al. (2012), avaliando fontes e dose de nitrogênio, não evidenciaram diferenças significativas na MS de plântulas para estes fatores, no entanto, ocorreram diferenças entres as cultivares testadas.

Comparando as fontes de nitrogênio utilizadas em cada parcelamento, são observadas diferenças apenas nos parcelamentos IV e $\mathrm{V}$, onde o maior acúmulo de MS foi proporcionado pela fonte líquida $(0,123 \mathrm{~g})$ e para o nitrato de amônio $(0,121 \mathrm{~g})$, respectivamente, (Tabela 5). A disponibilidade de nutrientes, principalmente nitrogênio, interfere a formação e a composição química das sementes, podendo afetar seu metabolismo e vigor (GLASS et al. 2002). Estudo avaliando a influência da fertilização nitrogenada no crescimento de trigo revelou maior acúmulo de MS em plântulas fertilizadas com nitrato $(1,05 \mathrm{~g})$, do que com amônia $(0,59 \mathrm{~g})$ (CRAMER \& LEWIS 1993). As respostas contrastantes quanto as fontes de nitrogênio aplicadas, revelaram que o nitrato de amônio apresentou menor variação entre os parcelamentos. Esta resposta pode estar relacionada ao melhor aproveitamento desta fonte de nitrogênio pelas plantas, quando comparado a ureia e a fonte líquida, principalmente devido as condições de alta umidade do solo e temperaturas amenas, observadas nos três estádios de aplicação. Segundo YANO et al. (2005), a eficiência do nitrato de amônia tende a ser superior as demais fontes nitrogenadas em alguns casos de aplicação superficial, principalmente em situações favoráveis para a volatilização, como alta umidade do solo, $\mathrm{pH}$ elevado e presença de palhada da superfície. Além disso, o nitrato de amônia apresenta disponibilidade mais prolongada no solo e baixo índice de salinidade, visto que é constituído por $50 \%$ $\mathrm{N}$-nítrico e $50 \% \mathrm{~N}$-amoniacal.

A taxa de nitrogênio residual no solo quando utilizado nitrogênio amídico, é de $15-30 \%$, enquanto a volatilização do mesmo pode variar de 1 a $47 \%$ (XU et al. 2015), fazendo com que a eficiência de absorção seja prejudicada, principalmente em condições de aplicação desfavoráveis como com altas temperaturas e baixa umidade do solo. Embora a aplicação de nitrogênio no emborrachamento tenha sido realizada com alta umidade no solo, não ocorreram precipitações significativas após a aplicação, o que pode ter favorecido a volatilização do mesmo, devido a não incorporação deste no solo.

\section{CONCLUSÕES}

O parcelamento do nitrogênio entre os estádios de emborrachamento e florescimento resulta em sementes com maior qualidade fisiológica, pois incrementa o percentual de germinação e os caracteres de vigor.

As fontes de nitrogênio, nitrato de amônia e fonte líquida se equiparam com a ureia em relação ao efeito na qualidade fisiológica das sementes, sendo alternativas interessantes para reduzir o custo de produção.

As cultivares TBIO Mestre e Quartzo evidenciaram sementes com maior qualidade fisiológica, em função do maior comprimento de radícula e percentual de germinação.

\section{REFERÊNCIAS}

ABRANTES FL et al. 2010. Nitrogênio em cobertura e qualidade fisiológica e sanitária de sementes de painço (Panicum miliaceum L.). Revista Brasileira de Sementes 32: 106-115.

ALVARES CA et al. 2013. Köppen's climate classification map for Brazil. Meteorologische Zeitschrift 22: 711-728.

BLOOM AJ et al. 2012. Deposition of ammonium and nitrate in the roots of maize seedlings supplied with different nitrogen salts. Journal of Experimental Botany 63: 1997-2006.

BRASIL. 2009. Ministério da Agricultura, Pecuária e Abastecimento. Regras para análise de sementes. Brasília: Mapa/ACS. 399p.

BRZEZINSKI CR et al. 2014. Nitrogênio e inoculação com Azospirillum na qualidade fisiológica e sanitária de sementes de trigo. Revista de Ciências Agrárias 57: 257265.

CARVALHO NM \& NAKAGAWA J. 1988. Sementes: ciência, tecnologia e produção. 3.ed. Campinas: Fundação Cargill. 424p.

CHEN A et al. 2014. Characteristics of ammonia volatilization on rice grown under different nitrogen application rates and its quantitative predictions in Erhai Lake Watershed, China. Nutrient Cycling in Agroecosystems 101: 139-152.

CRAMER MD \& LEWIS OAM. 1993. The influence of nitrate and ammonium nutrition on the growth of wheat 
(Triticum aestivum) and maize (Zea mays) plants. Annals of Botany 72: 359-365.

CRUZ CD. 2013. Genes: a software package for analysis in experimental statistics and quantitative genetics. Acta Scientiarum. Agronomy 35: 271-276.

CRUZ RP \& MILACH SCK. 2004. Cold tolerance at the germination stage of rice: methods of evaluation and characterization of genotypes. Scientia Agricola 61: 1-8.

DODD GL \& DONOVAN LA. 1999. Water potential and ionic effects on germination and seedling growth of two cold desert shrubs. American Journal of Botany 86: 11461153.

EMBRAPA. 2006. Empresa Brasileira de Pesquisa Agropecuária. Sistema Brasileiro de classificação de solos. 2. ed. Rio de Janeiro: Embrapa Solos. 306p.

FANAN S et al. 2006. Avaliação do vigor de sementes de trigo pelos testes de envelhecimento acelerado e de frio. Revista Brasileira de Sementes 28: 152-158.

GLASS ADM et al. 2002. The regulation of nitrate and ammonium transport systems in plants. Journal of Experimental Botany 53: 855-864.

GONDIM TCO et al. 2006. Avaliação da qualidade fisiológica de sementes de milho-crioulo sob estresse causado por baixo nível de nitrogênio. Revista Ceres 53: 413-417.

GUL H et al. 2012. Determination of seed quality tests of wheat varieties under the response of different sowing dates and nitrogen fertilization. Pakistan Journal of Nutrition 11: 34-37.

HAYASHI K et al. 2008. Ammonia volatilization from a paddy field following applications of urea: rice plants are both an absorber and an emitter for atmospheric ammonia. Science of The Total Environment 390: 485-494.

JACKSON LE \& BLOOM AJ. 1990. Root distribution in relation to soil nitrogen availability in field-grown tomatoes. Plant and Soil 128:115-126.

KOLCHINSKI EM \& SCHUCH LOB. 2004. Relações entre a adubação nitrogenada e a qualidade de grãos e de sementes em aveia branca. Ciência Rural 34: 379-383.

LIN CC \& KAO CH. 1995. NaCl stress in rice seedlings: Starch mobilization and the influence of gibberellic acid on seedling growth. Botanical Bulletin of Academia Sinica 36: 169-173.

PRANDO AM et al. 2012. Formas de ureia e doses de nitrogênio em cobertura na qualidade fisiológica de sementes de trigo. Revista Brasileira de Sementes 34: 272279.

RAMAGOPAL S. 1990. Inhibition of seed germination by salt and its subsequent effect on embryonic protein synthesis in barley. Journal of Plant Physiology 136: 621625.

SILVEIRA G et al. 2010. Efeito da densidade de semeadura e potencial de afilhamento sobre a adaptabilidade e estabilidade em trigo. Bragantia 69: 63-70.

STITT M et al. 2002. Steps towards an integrated view of nitrogen metabolism. Journal of Experimental Botany 53: 959-970.

SUPRAYOGI Y et al. 2011. Nitrogen remobilization and post-anthesis nitrogen uptake in relation to elevated grain protein concentration in durum wheat. Canadian Journal of Plant Science 91: 273-282.

TRIBOÏ E et al. 2003. Environmentally-induced changes in protein composition in developing grains of wheat are related to changes in total protein content. Journal of Experimental Botany 54: 1731-1742.

WARRAICH EA et al. 2002. Effect of nitrogen on grain quality and vigour in wheat (Triticum aestivum L.). International Journal of Agriculture \& Biology 4: 517-520. $\mathrm{XU} \mathrm{H}$ et al. 2015. Effect of nitrogen management during the panicle stage in rice on the nitrogen utilization of rice and succeeding wheat crops. European journal of agronomy 70 : 41-47.

YADVINDER-SINGH et al. 2015. Nitrogen management for zero till wheat with surface retention of rice residues in north-west India. Field Crops Research 184:183-191. YANO GT et al. 2005. Avaliação de fontes de nitrogênio e épocas de aplicação em cobertura para o cultivo do trigo. Semina: Ciências Agrárias 26: 141-148.

YIN XM et al. 2014. Effect of nitrogen starvation on the responses of two rice cultivars to nitrate uptake and utilization. Pedosphere 24: 690-698.

ZADOKS JC et al. 1974. A decimal code for the growth stages of cereals. Weed Research 14: 415-421. 